Farina Madita Dobrick

Jana Fischer

Lutz M. Hagen Editors

Research Ethics

in the Digital Age

Ethics for the Social Sciences

and Humanities in Times of

Mediatization and Digitization

SpringerVS 
Farina Madita Dobrick · Jana Fischer Lutz M. Hagen

Editors

Research Ethics

in the Digital Age

Ethics for the Social Sciences

and Humanities in Times of

Mediatization and Digitization

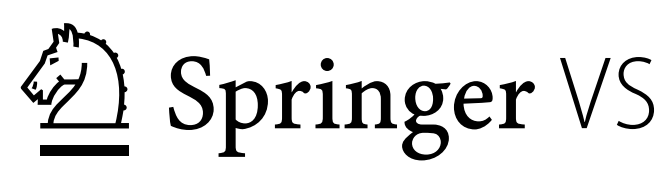




\section{Table of Contents}

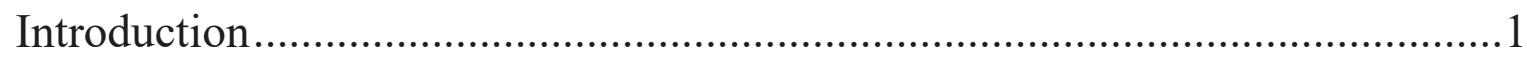

Jana Fischer, Farina Madita Dobrick, Lutz M. Hagen

\section{Keynotes as to Core Issues}

Research Ethics in the Digital Age: Fundamentals and Problems........................

Hermann Diebel-Fischer

What's Responsible For The Retraction Boom?

Adam Marcus, Ivan Oransky

Data Protection Laws, Research Ethics and Social Sciences

Anne Lauber-Rönsberg

Crowd-Based Documentation of Plagiarism: The VroniPlag Wiki

Experience.

Gerhard Dannemann

The Empowerment of Users: Rethinking Educational Practice Online

Pascal Marquet, Thomas Köhler

\section{Developing Research Standards in a Digitalized World}

Perception of Digital Methods' Ethics among Egyptian Researchers

Hesham Ahmed Faied

Rural India in the Digital Age... Manushi

Ethical Issues in Collecting Data from Informant of the Field 101 Sandrine M. Sidze, Thomas Koehler, Joerg Szarzynski 


\section{Digital Publishing}

'Getting What They Deserve': Digital Media Readers Comment on the Cause of Detroit's Bankruptcy....

Derek Roberts

Journalists on Twitter: Reconfiguring Professional Identity, Reconsidering

Research Ethics - The Case of Croatia

Iva Nenadic

Human Rights and the Regulation of Anonymity. New Challenges to Law and Research

Helga María Lell

Online and Offline: The Ethical Considerations of Researching the Use of Social Media by Traditional Journalists in Northern Nigerian Newsroom

Umar Suleiman Jahun

\section{Applying Research Ethics to Different Digital Environments}

Media Ethics in Research on Video-Based Mental Health Care

Nadine Schaarschmidt

Intersecting the Digital Maze. Considering Ethics in Cloud-Based

Services' Research

Daniel Kerpen, Matthias Dorgeist, Sascha Zantis

Research Ethics in the Doctoral Project "Boundary Management in

Social Media Communication".

\section{Jana Riedel}

Reflecting on Ethics in the Investigation of Online Communication during Emergencies

Eva Goldgruber, Julian Ausserhofer, Harald Hornmoen, Steen Steensen, Klas Backholm, Gudrun Reimerth, Elsebeth Frey, Rune Ottosen and Colin John McInnes 


\title{
The Empowerment of Users: Rethinking Educational Practice Online
}

\author{
Pascal Marquet ${ }^{1}$, Thomas Köhler ${ }^{2}$
}

Keywords: Online Learning, Digitization, Openness, Instrumental Conflict

\begin{abstract}
The conditions of school learning change globally. Teachers are faced with the challenge of either using digital media extensively in teacher training and school or allowing its usage. In order to develop an understanding of the meaning of such considerable change, authors first discuss the need for instructional design methods based on the way the users learn. While introducing the concept of instrumental conflict, a theoretical approach is applied, which helps to clarify the core structure of such processes. Finally, the successful example of adoption in the context of pharmaceutical education will be presented.
\end{abstract}

\section{Table of Contents}

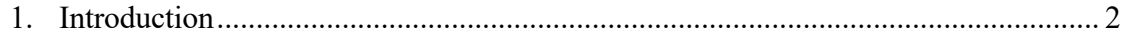

2. Promises of user/learner involvement in online education ........................................... 3

3. The need for instructional design methods based on the way the user learns ............ 7

4. The concept of instrumental conflict .................................................................... 8



6. A successful application of the instrumental conflict theory ……………................. 13

7. Conclusion: toward a better understanding of educational practice online ............... 14

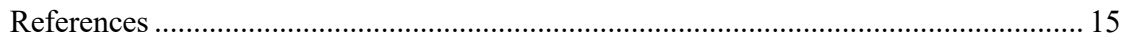

1 Pascal Marquet | Université de Strasbourg, FR | pascal.marquet@unistra.fr

2 Thomas Köhler | Technische Universität Dresden, DE | thomas.koehler@tu-dresden.de 


\section{Introduction}

It is rather difficult to obtain precise figures of trends in the current training and eLearning market- eLearning being understood as any activity by which learning content is partially or totally delivered by digital means, including Open and Distance Learning (ODL) platforms, Massive Open Online Courses (MOOCs) and Serious Games (SG) and which goes seriously beyond classic definitions as discussed by Köhler \& Ihbe (2006). More recent research suggest a continuous upcoming of innovations in technology enhance learning (Fischer et al., 2015; Bremer et al., 2016). Available forecast documents, which are mainly reports delivered by consultancy agencies or produced by international bodies, suggest that Western Europe is the second-largest market in the world after North America, and that global Western European 2016 revenues will be around $€ 7.3$ billion (Docebo, 2016) of the $€ 96.3$ billion for the entire world. By comparison, the video game industry should generate (only) approximately $€ 87$ billion in revenues in 2016 (Newzoo, 2016). Educational statistics, however, show that the adoption of digitization in the educational sector is rather heterogeneous and lacks behind in other branches (Pscheida et al., 2015). This rather late adoption will be addressed to some extent in the subsequent sections of this paper.

Although the amounts are likely unverifiable, these figures show that the $e$ Learning sector has surprisingly become more important than the gaming sector and that an increasing amount of people including students, workers and individuals, are now placed in the situation of being tempted or obliged to learn remotely. Learning remotely gives an overview of not only the existing industrial and business competition, but also the remaining scientific challenge. This situation can be seen as the consequence of the progressive invasion of Information and Communication Technology (ICT) in all activity sectors since the beginning of the 1970s. In fact, ICT has considerably reduced the duration of innovation cycles (from several years to several months, even weeks sometimes) due to the need for the industrialisation of a new product. This is particularly true in automotive sectors, which employ directly or indirectly approximately $9 \%$ of the working population in France (Le Monde, 2015) and 14\% in Germany (statement of German government, 2015 ). By analogy, ICT is now considered to be able to reduce the timeframe of adaptation of the working population to the requirements of the globalised economy and competition by increasing the level of competence without leaving the office or the factory (Edwards \& Usher, 2001). After having

3 Retrievable at: https://www.bundesregierung.de/Content/DE/Magazine/emags/economy/051/sp-2-die-automobilindustrie-eineschluesselindustrie-unseres-landes.html [March 11, 2017]. 
changed our production processes, digital means are now expected to serve our need for knowledge acquisition and competence development required by permanent innovation.

ICT is also considered to be a part of the solution for developing countries to reach the 2015 objectives for education, as defined in 1990 during the Jomtien World Conference on Education for All (UNESCO, 2014), and that still requires a good deal of effort from the countries concerned. In particular, the objective developing adult and continuing vocational education can benefit from the delivery of training content by digital means; in other words through $e$ Learning products of good quality, especially for teachers and teacher trainers. In this regard, the role of ICT in lifelong learning has been recently reaffirmed in the $E d$ ucation 2030 - Incheon Declaration (UNESCO, 2016).

In short, educational issues, as well as economic issues, are placing ICT in education and training as one of the main levers for the enhancement of the situation of people and countries. This subsequent enhancement is so that the design of Virtual Learning Environments (VLEs) becomes one of the key aspects of the success, but also the failure, of vocational education and lifelong learning. Of course, we do not claim to offer a solution to this complex problem. We are convinced, however, that if we want to have a chance to increase the quality and the observable effects on the knowledge acquisition and competence development of $e$ Learning products, and therefore on the adequacy of human resources to the social demand, this goes through the operationalisation of generic methods for designing these VLEs.

\section{Promises of user/learner involvement in online education}

The conditions of school learning change globally, not only in France or in Germany. Teachers are faced with the challenge of using digital media extensively in teacher training and school, or allowing and supporting their usage. Novel media concepts such as BYOD (Bring Your Own Device) or Open Educational Resources (OER) represent only the head of comparatively extensive development dynamics.

The following section does not examine the question of the pedagogical core of this development, but rather it investigates how working with free teaching and learning materials can be translated into everyday school life, as well as what this has to do with openness. We address five trends in a thesis-like manner that deals with: the difference between this new form of media in the school and conventional teaching and learning media, considers the usability in the school to finally discuss the basic conditions in teacher training, both in France and Germany. 
2.1 Openness: OER, $M O O C$, etc.

Learning objects are usually produced by specialized publishers and released for use by the responsible school authorities. The production of learning objects by the pedagogical specialists (i.e. teachers) in the preparation is limited to a few subordinate formats (panel, copies, test arrangements, etc.). Often, these are also copies of objects produced on the publisher's side rather than actually produced freely.

What is happening in the context of the new Openness? Educational materials (learning or knowledge objects) and educational institutions open up to any person who is interested in them, without having to prove access requirements or to obtain an authorization. This is a fundamental departure from previous education practice, institutional affiliation and limitation is questionable. The focus is on the interest in a topic or object, which is similar to a freely accessible library, but without the need for an organizational commitment (membership, enrolment).

UNESCO has devoted itself to the possibility of using OER as a new core element of a wide range of educational efforts, as the definition shows (2015):

"Open Educational Resources (OERs) are any type of educational materials that are in the public domain or introduced with an open license. The nature of these open materials means that anyone can legally and freely copy, use, adapt and re-share them. OERs range from textbooks to curricula, syllabi, lecture notes, assignments, tests, projects, audio, video and animation."

\subsection{User generation of content}

As mentioned in the previous section, the question of authorship is a central aspect for the creation of learning objects. Especially novel online platforms, such as Wikipedia, YouTube or blogs, lead to a change of the possibilities of use from the front desk to production. While traditional mass-media technologies, such as press, radio, television, production, is in the hands of a few specially qualified specialists, the picture is already changing with the introduction of the Internet. Online content can, in fact, be produced by almost everyone.

So what happens? Educational materials, learning and knowledge objects, as well as various other content, can be produced and published by anyone who is interested in it. Any potential interested person can also access these objects, insofar as the insights and interests of each individual can be shared with any other person. Learning is possible without teaching materials (e.g., schoolbooks) being provided by a teacher or produced by a small group of selected subjects (e.g., specialist).

The OECD-study on Participative Web: User-Created Content (2007) shows a collection of well-known tools of the so-called "Participation Web" that help the user of the Internet in creating contents of several formats easily. 
Moreover, the study defines the concept of the participative web as "based on an Internet increasingly influenced by intelligent web services that empower the user to contribute to developing, rating, collaborating on and distributing Internet content and customising Internet applications. As the Internet is more embedded in people's lives, 'users' draw on new Internet applications to express themselves through 'user-created content' (UCC)."

\subsection{Independence of learning behaviour}

How do learners use the new technological and organizational advancements? In looking at the learning behaviour, a new independence can be observed in a few key places. What is taken into account is how the lesson has to be looked at less clearly or not first hand by teachers. With a comparatively specific reference to the design of classroom situations in classical formats, this is referred to as Open Class, Virtual School, or Mobile Learning.

The question remains: what is happening? The community of learners is separated from the approach of a teacher-led activity to a learning-driven community. In this respect, the social moment is preserved, but the learner is more likely to take over control. This is because activities such at these can only be implemented according to their interests. Here, every learner can and must decide where, when, and whose learner experiences are most appropriate - but not necessarily follow the path set by the educational institution and its representative. Whether this is equally suitable for every learner is not assured (see for example Drummer, 2008). That such individual behaviour may be embedded into social contexts again is as well investigated in research (cp. Kahnwald \& Köhler, 2007) and discussed under the label of Microlearning, which may occur as changing information behaviour in virtual communities of practice.

\subsection{Socialization in new community forms - virtual loneliness versus virtual massiveness}

The basis of established teaching forms is a particular social organization. The school class, which is an especially designed large social group (as well as a spatial configuration), is typical for the school, or even constituting it, in addition to the division of roles between pupils and teachers. In line with the so-called small or working group, the school class is a social entity that operates on a faceto-face basis and is stable in regulation over a period of many years. This small group also differs from a project group. In some instances, even in higher school years, project groups are often found in class form alongside the regular groups.

What happens when, as described above, this strict localization is dissolved and online communities are formed? It can be observed that these are superimposed with classical learning communities, both temporally and spatially. This is surprising in that it can be assumed that online communication is less useful 
when individuals correspond face-to-face. However, this is obviously not applicable, as is shown by the widespread use of WhatsApp or Facebook-supported small groups. Also typical for an online community is the lack of limitation on the number of members as spatial barriers are eliminated. This increased number of members is also necessary because the invisibility of the other members (or learners) creates an uncertainty as to whether other persons are actually to be found and only a significantly larger number of mostly several hundred members of the members lead to a sufficient intensity of the exchange -as a result of the online research (Cheshire \& Antin, 2008).

Typical examples of these online forms of community in education are virtual learning communities when the learners encounter each other in an inverted or flipped classroom, or the communities of practice ("CoP", cf. Lave \& Wenger, 1991, Kahnwald \& Köhler, 2013).

\subsection{Data-based education: online, massive and even physiologically data based analytics}

The use of digital devices by learners leaves large data records (Big Data), even if this is not intended by the learner or lecturer. In fact, any interaction between the learners and the learning object leads to an information technology reaction, other than learning with a paper-based learning material. In most cases this data is not used. If learners or apprentices are aware of these data streams, the discussion also often turns around questions of data protection or fears of possible misuse. Up to this point, systematic use of these naturally occurring data for the regulation of the teaching-learning process has hardly been considered.

If, however, the pedagogical activity is continuously monitored and the data can be used for an immediate and long-term feedback process (e.g. online assessments), the possibilities for an individually tailored learning support are given. Conceptual examples of this are the 'Learning Analytics', the 'tailored training' or, in a certain way, the 'online assessment'. While the tailor-made training courses and also the online-based assessment only follow the idea of Big Data, this has clearly placed the focus on educational research with the concept of learning analytics. However, on the basis of the idea of Educational Data Mining (i.e. the fact that one can extract some useful connections from the multitude of randomly occurring data), these transformations are still in the children's shoes and can hardly be used in an everyday form - compare, for example, the study by Stützer and colleagues (2015) on social science analysis in higher education. 


\section{The need for instructional design methods based on the way the user learns}

For several decades, and with the introduction of ICT, the concept of ID has been widely used to highlight the need to think carefully about every learning situation mediated by digital devices (Baron, 2011; Henry, 2007). Paquette (2014) describes ID as a method or a process which helps to produce plans and models describing the organization of learning, teaching activities, resources and actors' involvement that comprise an instructional system or a learning environment. Merrill et al. (1996) defines it as an "instructional experience, which makes the acquisition of knowledge and skill more efficient, effective and appealing". In other words, ID is the process of conceiving a learning situation, which actually helps the learner to acquire new knowledge or develop new competences. This is different from learning design and, in particular, the approach proposed and developed by the IMS Global Learning Consortium, known as IMS-LD (Instructional Management Systems - Learning Design) which focuses on specifications of learning objects and activities in order to combine, generate and reuse digital resources that are described by a dedicated Educational Modelling Language (EML) (Koper \& Tattersall, 2005; Tattersall et al., 2005).

A multitude of ID methods have been developed in order to improve the practice of instructional designers. Among them, Esseff and Esseff (1998) focus on the design of simulations and performance activities (role play, demonstration case study). The regularly updated Systems Approach Model (Dick et al., 2013) focuses on the interrelationship between context, content, learning and instruction and the components of the learning system. The well-disseminated ADDIE model (Analysis, Design, Development, and Implementation) suggests that through an iterative process, the verification of the design documents saves time and money by identifying problems while they are still easy to solve. Most of the current models describing the ID process result from a variation of this last model.

If we look carefully at these models and/or methods, we can see that even if they can guide an instructional designer to design a learning situation, unfortunately, they cannot give information about the way the user experiences this learning situation. In other words, the learner's cognitive activity in the learning situation cannot be anticipated. 
Pascal Marquet \& Thomas Köhler

\section{The concept of instrumental conflict}

An extension of the instrumental genesis theory, adopted to learning situations supported by ICT

Historically, humans construct artefacts to meet a specific need. These artefacts become instruments only if they actually assume an effective application in the world in order to solve a precise problem or achieve an aim (Latour, 1987). In his instrumental genesis theory, Rabardel (1995) makes the same distinction between an artefact and an instrument but adds another distinction between manufactured material objects (tools) and symbolic objects (knowledge). The artefact is thus considered as an anthropological reality, while the instrument is the result of its use as a tool (Contamines, Georges \& Hotte, 2003). One can say, therefore, that the tool is an artefact itself, and that the term instrument can be used to establish the artefact as a means of realising the activity of the subject. Thus, it is the subject which confers upon the artefact the status of instrument. By extension, all cultural objects, such as human knowledge and tools, have common properties and are considered as artefacts and potential instruments when used by individuals.

The instrument is considered as a combination of attributes in one entity, with two facets relating to subject and artefact: On one hand, there is a process of transformation of the artefact in a situation - this is instrumentalisation, which is the attribution of a function to the artefact by the subject. On the other hand, there is the transformation of the subject at the cognitive level - this is instrumentation, which consists of the adaptation of the subject's knowledge to the artefact or the creation of new knowledge. These two processes are jointly involved in a reciprocal two-way relationship. They represent two inseparable dimensions of instrumental genesis. To synthesise, it is held that constructed cultural objects, be they material or symbolic, possess identical characteristics of which artefacts are made. Whenever a subject interacts with an artefact, an instrument emerges following a phenomenon of instrumental genesis, composed of a process running from the artefact towards the subject (which is instrumentation) and a process running from the subject towards the artefact (which is instrumentalisation) (cf. Fig. 1). 


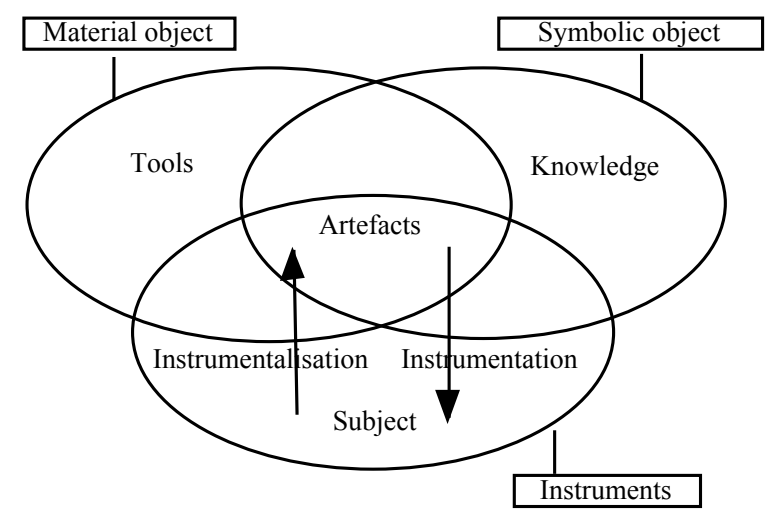

Fig. 1. The concepts of artefact, instrument and instrumental genesis.

Rabardel's (1995) theory provides the opportunity to consider knowledge in the process of being acquired in learning and teaching situations as much as the artefacts themselves. These artefacts, however, need to be sub-divided into $d i$ dactical artefact and pedagogical artefact. Didactical artefact is the term used here for all the disciplinary content which needs to be learned in order to become an instrument. Pedagogical artefact is defined here as the formalism for representation and/or the disciplinary content presentation scenario appropriate to its teaching. Formalism for representation is taken here to mean the semiotic processes of the designation of the didactical artefact, and presentation scenario is taken to mean the presentation of the didactical artefact, and it is also called the pedagogical scenario.

In distinguishing a didactical and a pedagogical artefactual dimension within knowledge taught, we make the same sort of distinction as Peraya (2002), who each time something is taught, sees it as being taught within a semio-pragmatic context, which understands the signifiers essential to its formulation which are situated in a discourse oriented towards the appropriation by the learner of the particular object being taught.

Duval (1995) also makes a distinction between two aspects of the same element of knowledge. He calls it noesis, a term which he borrowed from Plato and Aristotle, taken to mean the cognitive acts such as the conceptual understanding of an object, the discrimination of a difference or the understanding of an inference, and he indicates by semiosis the production of a semiotic 
representation. In the field of linguistics, this conception corresponds respectively to the signified and the signifier.

Two families of artefacts are thus present, one being the knowledge ordained by the situation, and the other being the discursive setting for learning. In order for one element of knowledge to be acquired effectively by the learner so that together they interact as an instrument, it is essential that the learner takes on board both the didactical understanding (content) and the pedagogical one (the formalism for representation and/or the presentation scenario). To use an analogy here, where some may see water, others see one atom of oxygen and two atoms of hydrogen, which together constitute a molecule of water.

A fundamental principle is, therefore, proposed here that every didactical object is associated with a pedagogical object in a teaching situation. Each of these objects, considered as an artefact, must be instrumentalised and instrumented suitably by the subject, i.e. the two concomitant phenomena of instrumental genesis have to be in operation. To put this in another way, the learner has to attribute the right functions at times to the content and to its formalism for representation, and he must also adapt his knowledge and apply it at times to the content and its formalism for representation. Acquiring knowledge becomes the double instrumental genesis of both didactical objects and pedagogical objects in a given situation.

The didactical and pedagogical traditions which have arisen, owing to the laws and regulations of teaching, and consequently since the industrialisation of teaching (Moeglin, 2005), have progressively determined how the majority of content should be presented in order for it to be assimilated by the greatest number of learners. It is a fact that these traditions are not always a great help when one wishes to introduce ICT into a learning and teaching situation.

In fact, things get even more complicated when didactical and pedagogical artefacts are associated with technical artefacts. For example, a software solution, a platform, or a website by which one gains access to academic or professional content is a technical artefact, which, to become a technical instrument has to be instrumentalised and instrumented by the user. As much as it may be a technical artefact, however, this VLE also brings into play the aforementioned didactical and pedagogical artefacts, which, in their turn, have to be suitably intrumentalised and instrumented in order to become real instruments, what can be considered as an overlay of three artefactual layers: didactical, pedagogical and technical (cf. Fig. 2). 


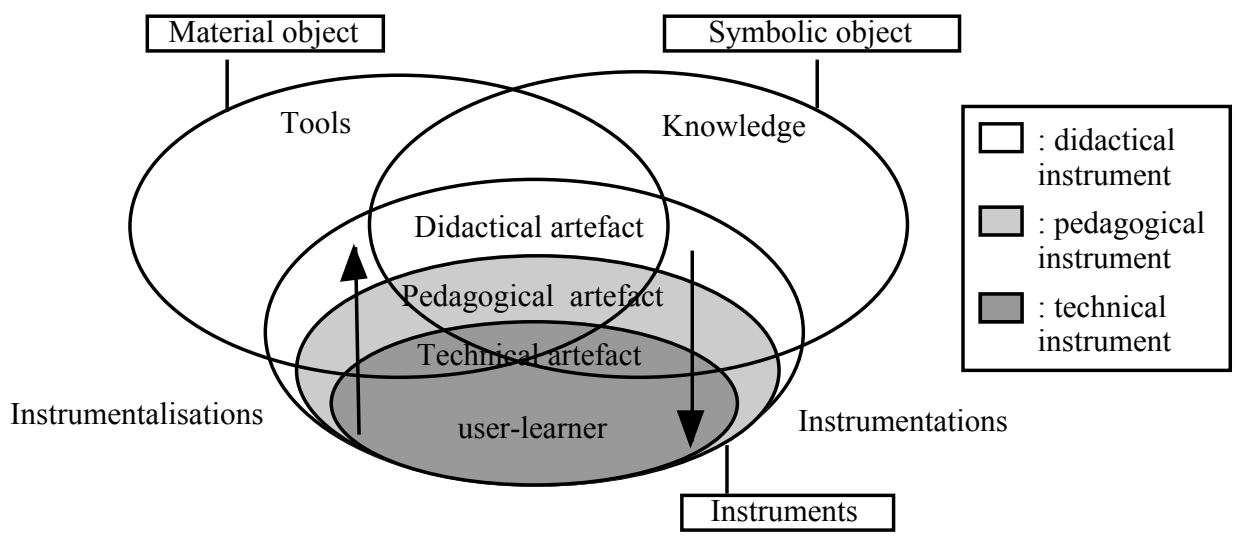

Fig. 2. Relationship of artefacts as sources of instrumental conflict.

Thus, the introduction of a technical system may provoke a disturbance of the balance between didactical and pedagogical artefacts, to the extent that the formalisms for representation and/or the representation scenarios which were pertinent beforehand are found no longer usable. These disturbances of the equilibrium may be termed instrumental conflicts, suggesting that the processes of instrumentalisation and instrumentation of the various artefacts in question can interfere with each other.

In an instrumented teaching and learning situation, each time one introduces a technical system, one takes the risk that the different levels of instrumental genesis may interfere with each another and deprive the learner at times of the possibility to respond to the situation and of constructing the didactical instrument as envisaged in the particular situation.

\section{The issue of avoiding instrumental conflicts}

Instrumental conflicts are thus interferences between the simultaneous processes of the instrumental genesis of didactical artefacts (disciplinary content), pedagogical artefacts (formalisms for representation and presentation scenarios) and technical artefacts (VLEs).

The first manifestation of instrumental conflicts, and without doubt the most usual, is what has been termed a rupture in the equilibrium between a classical situation and an instrumented one. This happens when combinations of didactical 
and pedagogical artefacts, tried and tested by academic tradition, find themselves to be no longer properly instrumentalised and instrumented once embodied in a technical system. This can occur each time that the disciplinary content is delivered within a VLE without modification being made to its presentation format or its role in learning. How many supposed $e$ Learning solutions turn out to be barely disguised slides or photocopies reformatted for the menu systems? No matter how much care has gone into the taught content, the computerisation of such matters requires that the learning and teaching scenario should be adapted in order that it can work with the constraints imposed by the system. In the absence of such precautions, the addition of a technical artefactual layer to a former relevant combination of didactical and pedagogical artefacts is bound to lead to instrumental conflict.

The second type of manifestation of instrumental conflicts corresponds with what can be observed when disciplinary content has not been suitably adapted to the generic application which diffuses it. This is the case, and unfortunately it is not altogether rare when a distance education platform not only imposes its own functionalities, but also forces a particular pedagogical scenario. A certain number of Learning Management Systems are built around modes of organisation of pedagogy which are not all suitable for all academic disciplines or all professional training contexts. These modes of organisation of pedagogy cover a broad range, which extends from the downloading of files to print and be read in complete seclusion to systems of collaborative learning with tutor support and computer sessions. Neither these extremes nor the possibilities between are, a priori, good or bad. They can become one or the other depending upon the functioning of the content presented when they fail to accommodate the nature of the teaching concept and the learning vehicle provided by the platform.

The third and final manifestation of instrumental conflicts occurs when a technical system dedicated to a family of didactical objects is used inappropriately by the learner or the trainer. In this instance, neither the contents involved nor the VLE functionalities are to blame, but rather the pedagogical expertise of the teacher. This happens, for example, when teachers are delivering sessions on dynamic geometry by relying upon scenarios developed for paper-pencil geometry. In doing this, pupils cannot access the properties of the geometric objects that the software emphasises, since it is precisely these properties that are not updated in the same way in relation to how the software is used or how one produces figures by hand.

From the moment when one of the didactical, pedagogical or technical artefacts is not in place, or, to put it another way, is not in harmony with the two others, the processes of instrumentalisation and instrumentation necessary for the construction of knowledge risk becoming the object of instrumental conflict. 


\section{A successful application of the instrumental conflict theory}

According to the instrumental conflict theory, effective learning is the result of an ID process that takes each artefact into consideration - technical, pedagogical and didactical - in order to adapt them to each other. As mentioned earlier, this same issue has been confirmed in the TPACK theory (Koehler \& Mishra, 2009). The three artefacts should be intersected with each other so that they achieve the best adaptation and then more potential effective learning.

LabQuest Pharma ${ }^{\circledR}$ is a serious game (SG) that aims to teach professional skills to workers wishing to acquire specific know-how in the field of pharmaceutical production (Denami, 2016a; 2016b). This SG reproduces a standard production unit in a plant and simulates the behaviour of the operator, who is in charge of monitoring the automated production of any pharmaceutical product that needs an environment conditioned by air filtration in order to prevent the intrusion of particles. Access to this environment demands rigorous training that consists of numerous sessions to acquire basic knowledge in biology, operating knowledge about the automated production unit and procedures of control, and report of the production process. In the LabQuest Pharma ${ }^{\circledR}$ environment, the user-learner is the operator and can virtually experiment all sorts of situations regarding the scrupulous observation of standards of hygiene, dress and behaviour.

The ID method used for developing the SG has been based in the identification of the most relevant artefacts belonging to the three associated families of didactical, pedagogical and technical objects. In the first phase, we have identified and compiled an inventory of the procedures, gestures and standards of the aseptic zone activity. According to Cizeron (2010), information has been collected from: (1) interviews with the leading personnel of three sites of different sizes and manufacturing different products, the goal being to collect their expectations regarding the work of their employees; (2) the textbook analysis of reference in order to derive standards and fundamental rules (European Commission, 2011); and (3) interviews with employees of the same production sites in order to have real workers' testimonies. A set of actions, procedures, and standards have been chosen to be integrated into the simulator in accordance with the available techniques. The simulator offers 10 professional gestures (dressing, surface cleaning, etc.) and 60 items.

In the second phase, we have designed the scenario based on the following requirements: (1) to reproduce a typical day's production by defining the basic steps common to all factories; (2) to integrate the rules, standards and gestures that are common to all target factories; (3) to reproduce a common type environment; and (4) to integrate professional practices that are also common to all target 
sites. A scoring algorithm was developed according to the prioritisation of tasks (in order of importance) characterising a procedure. Other factors were also considered: the elapsed time, the number of hesitations, and the progress in performance.

The third and final phase has been the realisation of the human-machine interface. It includes options to interact with objects, the environment and the avatar that represents the user-learner in the VLE. The interface was designed in line with intuitiveness and simplicity criteria to reduce the difficulties related to the use of the simulator. For example, when an object is selected, it appears at the bottom of the screen in the virtual user's hands; the displacement of an object is done by drag and drop to the place of destination. In this phase, numerous usability tests have been implemented in order to improve the ergonomics of the simulator.

In order to verify or disprove the better efficiency of using LabQuest Pharma ${ }^{\circledR}$ for training professional skills, a one-factor (learning professional gestures with the SG versus classical training) pre-post-test protocol with a sample of 45 people who have never worked in an aseptic zone has been designed. The results showed that $87.6 \%$ of the subjects who completed the LabQuest Pharma ${ }^{\circledR}$ protocol correctly succeeded in accomplishing gestures and procedures in the post-test phase, while $57.5 \%$ of the subjects trained with the traditional method succeeded in doing so (see Denami, 2016a, for more details).

In addition to the validation of the SG for training sessions and its commercial interest based on its training validity, the design of LabQuest Pharma ${ }^{\circledR}$ has shown that designing a VLE that combines relevant didactical, pedagogical and technical artefacts, so that they become instruments without generating instrumental conflicts, enables the implementation of didactical objects that were not treated in classical training sessions, mainly professional gestures (procedural knowledge) rather than reasons why things should be done to respect such a procedure (declarative knowledge). In particular, the analysis of work activity enabled the identification, collection, analysis and selection of the fundamental contents to design the training tool (Samurçay \& Pastré, 2010). The instrumental conflict concept then shaped the method of selection and adaptation of contents to digital technologies in a bi-directional way: the contents were selected according to available digital technologies and, in the same way, the choice of technologies was influenced by the new content possibilities.

\section{Conclusion: toward a better understanding of educational practice online}

The development of LabQuest Pharma ${ }^{\circledR}$ has confirmed the interest in the concept of instrumental conflict in ID; however, above all, the main interest in VLEs 
is to implement new learning objects that were not reachable with traditional 2D technologies, such as paper-pencil/blackboard-chalk/handbook-teacher. In retrospect, it can be considered that most of the contents taught today are those that are compatible with the printing industry and writing by hand. Although many innovative ways of delivering content can benefit from the use of ICT (Sharples et al., 2015), by exploiting connectivity between learners' event/content-based learning opportunities and learning by doing experiences, they all aim to optimise existing teaching techniques supported by ICT. This, for instance, is the case for peer-assessment in MOOCs and flipped classrooms in blended learning programmes.

Recent changes in teaching practice and learning conditions listed above also suggest that openness, as provided by OERs and further approaches need to be usable as well as to be available. Their use by learners and, occasionally, difficulties encountered by learners while using them, can be explained by instrumental conflicts. But, more interesting, their design can benefit from the distinction between didactical objects and pedagogical (re)presentation of these objects to be used online. Altogether this calls for the application of suitable theoretical paradigms that reach beyond classic learning theories on the one hand and is not completely limited to the educational domain.

On the other hand, such new understanding of socio-technological conditions needs extension by additional consideration of framing institutional circumstances which has rarely been discussed in educational literature and was rather a topic of some sociological, organizational and business studies. Obviously such analysis does not necessarily demand a modelling by neither computational or information science neither media technology.

However when investigating the educational practice (cf. for example Misoch \& Köhler, 2006) one remaining challenge is to educate and train teachers in a way that allows them to apply such renewed analytical understanding in their daily practice when applying digital technologies in and outside the classroom. Authors intended to open up education-theoretical reflection by rethinking educational practice online toward an empowerment of its users.

\section{References}

Baron, G.-L. (2011). Learning design. Recherché et formation,68, 109-120.

Bremer, C., Ebner, M., Gumpert, A., Hofhues, S., Döbeli Honegger, B., Köhler, T., Lorenz, A., \& H.W. Wollersheim (2016): Mediale Megatrends und die Positionierung der Hochschulen; In: Wachtler, J., Ebner, M., Gröblinger, O., Kopp, M., Bratengeyer, E., Steinbacher, H.-P., Freisleben-Teutscher, C. \& Kapper C. (eds.) Digitale Medien: Zusammenarbeit in der Bildung; Reihe: Medien in der Wissenschaft, Band 71; Münster Waxmann. 
Cheshire, C. \& Antin, J. (2008). The Social Psychological Effects of Feedback on the Production of Internet Information Pools. Journal of Computer Mediated Communication, DOI: 10.1111/j.1083-6101.2008.00416.x

Cizeron, M. (2010). Le geste professionnel comme concept et outil d'analyse. M. Cizeron \& N. GalPetitfaux (eds.), Analyse des pratiques: Expérience et gestes professionnels (257-268). Clermont-Ferrand, France: Presses de l'Université Blaise Pascal. .

Contamines, J., Georges, S. \& Hotte, R. (2003). Approche instrumentale des banques de ressources éducatives. Sciences et Techniques Educatives, hors série, 157-177.

Cuban, L. (2001). Oversold and underused: Computers in the classroom. Cambridge: Harvard University Press.

Denami, M. (2016a). Simulation: A powerful tool for training professional skills in cleanrooms. Pharmaceutical Technology in Hospital Pharmacy, 1(1), 45-53.

Denami, M. (2016b). Un Serious Game pour le développement des compétences professionnelles des opérateurs en zone aseptique: Définition d'un modèle holistique de conception et études d'usage. $\mathrm{PhD}$. Université de Strasbourg.

Dick, W., Carey, L. \& Carey J.O. (2013). Systematic Design of Instruction: Pearson New International Edition [ebook]

Docebo (2016). ELearning market trends and forecast 2014-2016 report. Dubai.

Duval, R. (1995). Sémiosis et pensée humaine. Registres sémiotiques et apprentissages intellectuels. Berne, Switzerland: Peter Lang.

Edwards, R. \& Usher, R. (2001). Lifelong learning: A postmodern condition of education? Adult Education Quarterly, 51(4), 273-287.

Esseff, P.J. \& Esseff, S.M. (1998). Instructional Development Learning System (IDLS). 8th ed. ESF Press.

European Commission (2011). Good Manufacturing Practices (GMP) guidelines. Retrievable at: http://ec.europa.eu/health/documents/eudralex/vol-4/index en.htm [March 08, 2017].

Fischer, H., Heise, L., Heinz, M., Möbius, K., Köhler, T. (2015): Let's Look to Future! E-LearningTrends and Hypes in Academic Teaching. In: EURODL - European Journal of Open, Distance and E-Learning. Special Issue Best of EDEN 2013-2014, S. 129-140. Retrievable at: http://www.eurodl.org/materials/special/2015/Zagreb_Fischer_et_al.pdf.

Gartner (2015). The hype cycle. Interpreting Technology Hype. Retrievable at: http://www.gartner.com/technology/research/methodologies/hype-cycle.jsp [March 08, 2017].

Henry, F. (2007). Pratique de design pédagogique et instrumentation du concepteur. M. Baron (ed.), Environnements informatisés et ressources numériques pour l'apprentissage (229-254).Paris: Hermes-Lavoisier.

Kahnwald, N. \& Köhler, T. (2007). Microlearning in Virtual Communities of Practice? An explorative analysis of changing information behaviour. Micromedia \& eLearning 2.0: Getting the Big Picture. Proceedings of Microlearning 06. Innsbruck: University Press.

Koehler, M.J. \& Mishra, P. (2009). What is technological pedagogical content knowledge? Contemporary Issues in Technology and Teacher Education, 9(1), 60-70.

Köhler, T. \& Ihbe, W. (2006). Möglichkeiten und Stand der Nutzung neuer Medientechnologien für die akademische Lehre. Überlegungen zur aktuellen Situation an der TU Dresden; Wissenschaftliche Zeitschrift der Technischen Universität Dresden, 1-2. 
Köhler, T. \& Kahnwald, N. (2013). Online Communities: Enterprise Networks, Open Education and Global Communication. Proceedings of the GeNeMe 2013; Dresden, TUDPress. Retrievable at: http://nbn-resolving.de/urn:nbn:de:bsz:14-qucosa-153950 [March 08, 2017].

Koper, R. \& Tattersall, C. (2005). Learning Design: A Handbook on Modelling and Delivering Networked Education and Training. Springer Verlag: Berlin.

Latour, B. (1987). Science in action. Cambridge, MA: Harvard University Press.

Lave J. \& Wenger E. (1991). Situated Learning: Legitimate Peripheral Participation. Cambridge University Press: Cambridge.

Le Monde (2015). Le Monde, [online] 10 October. Retrievable at: http://www.lemonde.fr/les-decodeurs/article/2015/10/22/le-secteur-automobile-ne-represente-pas-9-des-emplois-francais 4794416 4355770.html [March 03, 2017].

Merrill, M. D., Drake, L., Lacy, M. J. \& Pratt, J. (1996). Reclaiming instructional design. Educational Technology. 36 (5), 5-7.Misoch, S. \& Köhler, T. (2006). Neue Medien in der Lehrerbildung: Beobachtungen zur aktuellen Nutzung an der Universität Potsdam. In: LLF Berichte, Lernen und Neue Medien, 21.

Moeglin, P. (2005). Les industries éducatives. Paris, France: PUF.

Newzoo (2016). 2016 global games market report. San Francisco.

OECD (2007). Participative Web and User-Created Content: Web 2.0, Wikis and Social Networking; Paris, OECD. Retrievable at: http://browse.oecdbookshop.org/oecd/pdfs/free/9307031e.pdf [September 10, 2015].

Paquette, G. (2002). L'ingénierie pédagogique, pour construire l'apprentissage en réseau. Montreal, Canada: Presse de l'Université du Québec.

Paquette, G. (2014). Technology-based instructional design: Evolution and major trends. J.M. Spector, M.D. Merrill, J. Elen \& M.J. Bishop (eds.), Handbook of research on educational communications and technology (661-671). New York, NY: Springer.

Peraya, D. (2002). Le cyberespace: Un dispositif de communication et de formation médiatisée. S. Alava (ed.), Cyberespace et formations ouvertes. Vers une mutation des pratiques de formation? (17-44). Brussels, Belgium: De Boeck.

Pscheida, D., Minet, C, Herbst, S, Albrecht, S. \& Köhler, T. (2015). Use of Social Media and Onlinebased Tools in Academia. Results of the Science 2.0-Survey 2014. Dresden: TUD Press. SLUB. Retrievable at: http://nbn-resolving.de/urn:nbn:de:bsz:14-qucosa-191110 [March 09, 2017].

Rabardel, P. (1995). Les hommes et les technologies, approche cognitive des instruments contemporains. Paris, France: Armand Colin.

Samurçay, R. \& Pastré, P. (2010). Recherches en didactique professionnelle. Toulouse, France: Octarès Éditions.

Sharples, M., Adams, A., Alozie, N., Ferguson, R., FitzGerald, E., Gaved, M., McAndrew, P., Means, B., Remold, J., Rienties, B., Roschelle, J., Vogt, K., Whitelock, D. \& Yarnall, L. (2015). Innovating pedagogy 2015: Open University innovation report 4. Milton Keynes: Open University.

Stützer, C. M., Breiger, R. \& Köhler, T. (2015). Social Academic Analytics in Higher Education. Abstracts of the Sunbelt XXXV International Sunbelt Social Network. Brighton: ISNA Publishers. Retrievable at: http://insna.org/sunbelt2015 [March 09, 2017].

Tattersall, C., Vogten, H., Brouns, F., Koper, R., Van Rosmalen, P, Sloep, P. \& Van Bruggen, J. (2003). Delivering courses modelled using IMS Learning Design. Heerlen: OUNL. Retrievable at: http://dspace.ou.nl/bitstream/1820/35/2/LD-delivery.pdf [March 07, 2017]. 
UNESCO (2014). Education for all global monitoring report. Paris, France: UNESCO.

UNESCO (2015). What are Open Educational Resources? Retrievable at: http://www.unesco.org/new/en/communication-and-information/access-to-knowledge/openeducational-resources/what-are-open-educational-resources-oers [March 07, 2017].

UNESCO (2016). Education 2030 - Incheon Declaration. Paris, France: UNESCO. 